\title{
Determination of Scopolamine by Gas Chromatography from Different Parts of the Datura innoxia Biomass
}

\author{
GEORGIANA MARDARE (BALUSESCU), TEODOR MALUTAN*, LILIANA LAZAR \\ "Gheorghe Asachi" Technical University of Iasi-Romania, "Cristofor Simionescu" Faculty of Chemical Engineering and \\ Environmental Protection, Department of Natural and Synthetic Polymers, 73 Prof. Dimitrie Mangeron Blvd., 700050, Iasi, \\ Romania
}

\begin{abstract}
Tropane alkaloids are characteristic secondary metabolites which occurred mainly in Solanaceae plant family. Among them, hyoscine or scopolamine is one of the predominant in the Datura species, occurring in all plant organs (vegetative and reproductive). Because of its medical use and toxic properties, a rapid, convenient and reliable method is essential for the quantification of scopolamine content of plant biomass. The aim of this study was to elaborate a rapid method for determination of scopolamine from Datura innoxia, using Soxhlet extraction and quantification by gas-cromatography with flame ionization detection. Scopolamine content was investigated in plant organs (leaves, flowers, fruits, stem end root) of Datura innoxia collected in the maturity period from a country side region from Romania. Scopolamine was found in all organs examined. The results revealed that, concentration of scopolamine extracted in ethanol followed the order: root > seeds > flowers > stem > leaves. Higher extraction efficiency of scopolamine was found for 1-butanol compared to ethanol, and the order of concentration was: flowers > seeds > leaves > stem > root. Scopolamine content showed differences indicating that it is influenced by: 1) plant biomass as place of growing, plant species, plant organ and 2) extraction process efficiency based on polarity of the solvent, extraction time and sample - solvent ratio. The results show clear evidence that, the highest scopolamine content was found in 1-butanolic extracts and lowest in ethanolic extracts.
\end{abstract}

Keywords: GC-FID, scopolamine, tropane alkaloids, Soxhlet extraction, ethanol, 1-butanol

\section{Introduction}

Higher plants $(\sim 300000$ plant species in the world), are recognized to be an inexhaustible resource of bioactive compounds which contain hundreds of chemical constituents [1,2]. Moreover, as sources of medicinal compounds, have continued to play an important role in maintaining human health, providing novel chemical entities (NCE) with potential for pharmacological applications [3]. Typical plant bioactive compounds are secondary metabolites (alkaloids, phenolics, terpenoids, etc.) that may cause pharmacological or toxicological effects in humans and animals [4].

Searching for new secondary metabolites from plant biomass implies qualitative and quantitative phytochemical screening of the extracts for the presence of new compounds of interest. The road that leads from plant biomass to target compound it is long-term, involves work and includes several steps which follow the pathway: collection of the plant biomass $\rightarrow$ authentication $\rightarrow$ cleaning $\rightarrow$ drying and storage $\rightarrow$ selection of the solvents $\rightarrow$ extraction procedures [5-12] $\rightarrow$ analysis of the extracts $[11,13,14] \rightarrow$ structure elucidation $[2,15,16] \rightarrow$ phytocomplex / target compounds $[2,17,18]$.

One of the most representative group of secondary metabolites is represented by alkaloids. Tropane alkaloids, more then 200, represent a group of secondary metabolites which occur naturally in several plant family, mainly in the genera of Solanaceae family (genus Datura) and are often used in medicine as various remedies [1]. The one of the main representative tropane alkaloids in Datura species is scopolamine, also called hyoscine. Scopolamine has been investigated during the last two decades, but a few data are presented regarding the quantification using $\mathrm{GC}$ technique.

*email: thmalu@tuiasi.ro 
The first determination of tropane alkaloids using GC analysis was performed in 1960. Today, the most powerful tools used to separate tropane alkaloids are chromatographic techniques $[1,15,19]$.

Quantitative and qualitative analysis had been applied for determination of tropane alkaloids in various Datura plant species using GC and GC/MS techniques. Recently, some investigation of Datura species using the GC/MS analysis demonstrate that it is the method of choice for a large number of tropane alkaloids which are not detected by other methods and are identified without using of standard compounds [16, 20-28]. On the other hand, GC/FID technique is much less applied for quantification of tropane alkaloids.

An important aspect of natural compounds is the optimization of extraction parameters [1]. In order to obtain the maximum efficiency, several parameters were evaluated starting to extraction protocols applied to Datura innoxia biomass (leaves, flowers, seeds, stem and root): (1) selection of the extraction techniques - Soxhlet extraction (Hot Continuous Extraction) has the ability to extract the largest quantity of sample and extraction efficiency can be great even when target compounds have limited solubility in the solvent employed. It is influenced by important factors such as the polarity of the solvent (the most important factor), temperature, solid - solvent ratio and extraction time (as the extraction time is higher the more efficient extraction is) $[5,18,29,30]$; (2) polarity of the solvents - in general selection of solvent should be in accordance with the chemical nature of the targeted compounds. For instance; polar solvents (ethanol, methanol, ethylacetate, etc.) are used for extraction of hydrophilic components in plants, whereas non-polar solvents (hexane, ether, petroleum ether, etc.) are preferred for extraction of lipophilic secondary metabolites [31,32]; (3) characterization of the compound - Solanaceous taxa are well-known producers of classical lipophilic tropane. Scopolamine or Hyoscine is a non-polar, datura tropane alkaloid, with chemical formula $\mathrm{C}_{17} \mathrm{H}_{21} \mathrm{NO}_{4}$ and molecular weight 303.35. Hyoscine pure standard is soluble in ethanol $(96 \%)$ and water $>100 \mathrm{mg} / \mathrm{L}$, with melting point $66-70^{\circ} \mathrm{C}$ and toxicity LD oral rat $2650 \mathrm{mg} / \mathrm{kg}$ [33-35] and (4) gas chromatographic condition - separation efficiency of the target compound (scopolamine) from interfering biomass peaks was achieved by adequate adjustments of the temperature gradient.

For this study we select Datura innoxia biomass from Romania in order to apply the steps following the pathway which leads us to the identification of the compound of interest (target compound).

Datura species, indigenous plant from America and Asia, belongs to the Solanaceae family and are outspreaded in Europe, especially as medicinal and ornamental plants and are well known for tropane alkaloids content [15]. Today experts classify Datura into nine different species: Datura ceratocaula, Datura discolor, Datura ferox, Datura innoxia, Datura leichhardtii, Datura metel, Datura quercifolia, Datura stramonium and Datura wrightii [19]. This plant species have become important for medicine, especially Datura metel and Datura innoxia for their rich scopolamine content. Scopolamine is used for the treatment of asthma or sialorrhea, skin eruptions, colds, nervous disorders, neuro-sedative Parkinson's disease and motion sickness. Moreover, this tropane alkaloid is an antispasmodic, antiasthmatic, narcotic, antimicrobial agent and also used as analgesics, narcotics, sedatives, as well as in treatment for surgical procedures [15,36].

Datura innoxia, known in Romania as the improper name, angel's trumpet, is a perennial plant, dicotyledonous [37], woody that grows in the form of bushes reaching a height of 2 meters. The dark green or purple leaves have a length of $20-30 \mathrm{~cm}$ with an asymmetrical base. The large white flowers are $20 \mathrm{~cm}$ to $30 \mathrm{~cm}$ long and bloom at sunset. Approximately 200 seeds are kidney-shaped and grow as thorny pods at short distances from each other. She grows most often at ground level in abandoned areas, on roadsides across the continent [19] or as ornamental plants in people's yards. We can appreciate that gardening practices in a community could provide opportunities for experimentation and new leads for obtaining new phytochemical compounds. Nowadays, several studies revealed that Datura innoxia has a huge potential for antibacterial, anticancer, antioxidant properties [38].

Taking into account the information rewired, the main objective in this study was to investigate Datura innoxia biomass (leaves, flowers, fruits, stem and root) from Ramnicu Sarat, Romania for 
identification and quantification of scopolamine based on conventional extraction method (Soxhlet extraction) and GC analysis. To bring in public attention the advantages of this conventional extraction, for this work we select two solvents, ethanol end 1-butanol.

\section{Materials and methods}

\subsection{Chemicals and reagents}

Analytical standard of pure hyoscine (scopolamine) ( $\geq 99 \%)$ was purchased from Sigma Aldrich and ethanol (HPLC analytical grade) for calibration was purchased from Sigma Aldrich (Darmstadt, Germany). The solvents used ethanol (96\%) and 1-butanol (99.6\%), used to assist the Soxhlet extraction process, was reagent grade and purchased from Chemical Company, Romania. Solvent selection was performed according to their properties (polarity, boiling point, dielectric constant and density). In Table 1 are presented the physical proprieties of these solvents [39].

Table 1. Organic solvents with their physical constants

\begin{tabular}{ccccc}
\hline Solvent & $\begin{array}{c}\text { Chemical } \\
\text { formula }\end{array}$ & $\begin{array}{c}\text { Boiling point, tbp } \\
\left({ }^{\circ} \mathbf{C}\right)\end{array}$ & Dielectric constant, $\mathbf{r}$ & Density $\left(\mathbf{g} / \mathbf{c m}^{-\mathbf{3}}\right)$ \\
\hline 1-Butanol $(99.6 \%)$ & $\mathrm{C}_{4} \mathrm{H}_{8} \mathrm{OH}$ & 117.7 & 17.51 & 0.81 \\
Ethanol $(96 \%)$ & $\mathrm{C}_{2} \mathrm{H}_{5} \mathrm{OH}$ & 78.3 & 24.55 & 0.81 \\
\hline
\end{tabular}

\subsection{Plant material}

Datura innoxia leaves, flowers, fruits, stem and root were collected at the maturity periods in October - November 2018. Fruits were peeled by hand, separating the capsule from seeds. The collected biomass were air-dried and stored in the laboratory at room temperature. The dry samples were homogenized in a mechanical grinder into a powdered form. The powder was placed in a sealed plastic container and stored for later use.

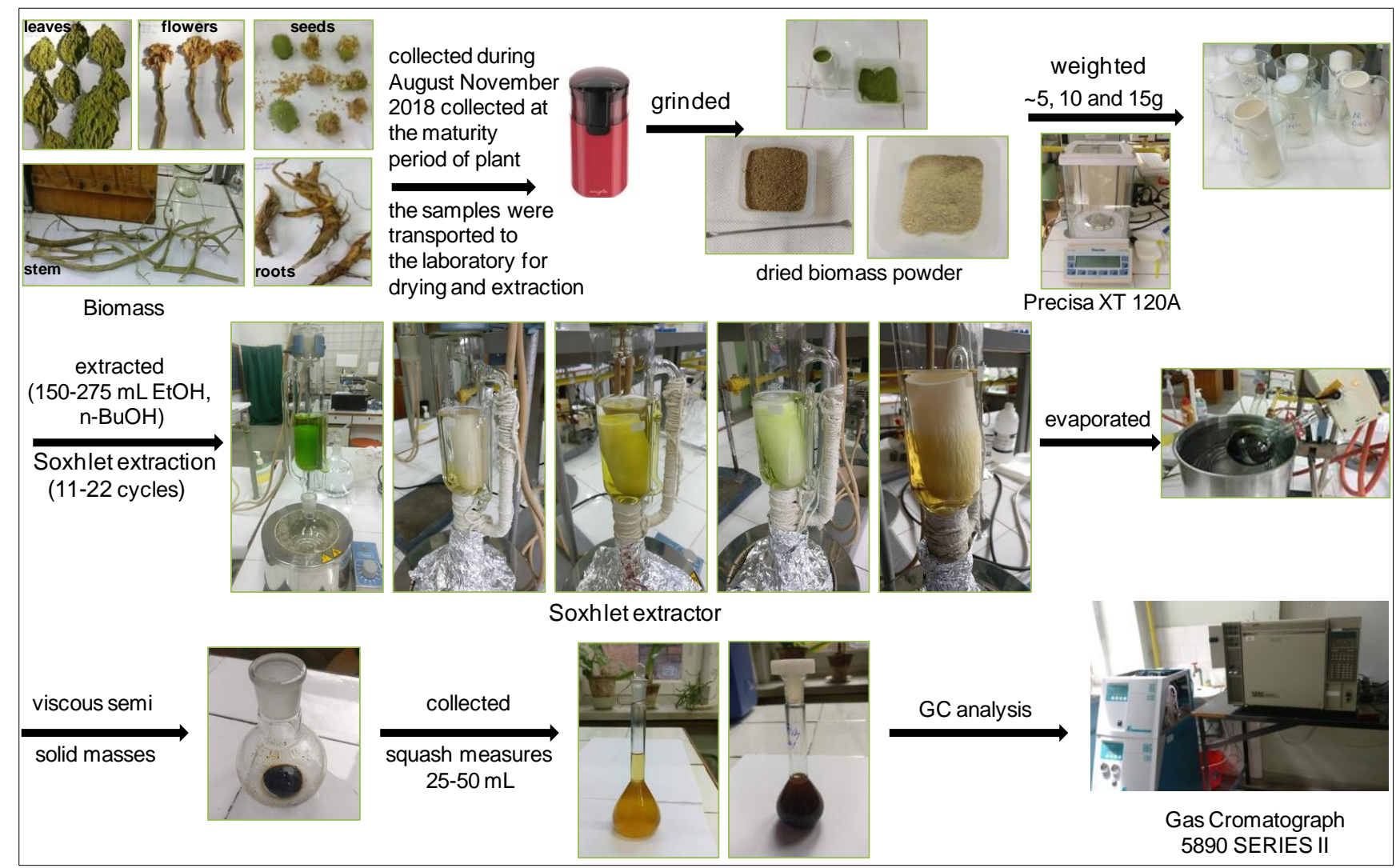

Figure 1. Sample preparation and gas chromatography analysis of the extracts 


\subsection{Alkaloid extraction}

The powder dried biomass of Datura innoxia, approximate 5 grams for flowers and root, 10 grams for stem and 15 grams for leaves and seeds, was extracted by using Soxhlet extractor with $150-250$ $\mathrm{mL}$ of ethanol $(96 \%)$ and 1-butanol $(99.6 \%)$. Sample solvent - ratio as 3:50 w/v (leaves), 1:30 w/v (flowers), 3:50 w/v (seeds), 2:30 w/v (stem) and 1:30 w/v (root) of the dried powder was selected for this Soxhlet extraction process. The extraction process was run between $11-22$ hours and set at $80{ }^{\circ} \mathrm{C}$ for ethanol extraction and $117^{\circ} \mathrm{C}$ for 1-butanol extraction. The solvent was evaporated by a rotary evaporator at $80{ }^{\circ} \mathrm{C}$ for ethanol to obtained viscous semi solid masses. For 1-butanol the evaporation was performed using a sand thermostatic bath set at $120^{\circ} \mathrm{C}$. The semi solid extracts were transferred to measuring bottles and diluted to the sign with the extracting solvent. Each sample was stored at $3{ }^{\circ} \mathrm{C}$ and then $10 \mu \mathrm{L}$ from each extract was used for gas chromatography analysis. Three replicates were performed. A schematic illustration of preparative steps for Datura innoxia dried biomass is presented in Figure 1.

\subsection{Gas chromatography (GC)}

Quantitative analysis were performed using a 5890 SERIES II gas chromatograph equipped with a $30 \mathrm{~m} \times 0.32 \mathrm{~mm}$ internal diameter, $0.25 \mu \mathrm{m}$ film thickness SPB-1 Supelco capillary column. Nitrogen was used as the carrier gas with a flow rate of $0.5 \mathrm{~mL} / \mathrm{min}$. The split ratio was $1: 100$, and the injection volume was $10 \mu \mathrm{L}$. The injector temperature was held at $280^{\circ} \mathrm{C}$ and flame ionization detector temperature was held at $250^{\circ} \mathrm{C}$. Temperature program for oven was as follow: $100^{\circ} \mathrm{C}$ for $1 \mathrm{~min}$, then $15^{\circ} \mathrm{C} / \mathrm{min}$ ramp to $180^{\circ} \mathrm{C}$ (held for $5 \mathrm{~min}$ ), followed by $5^{\circ} \mathrm{C} / \mathrm{min}$ ramp to $300^{\circ} \mathrm{C}$ and held at the final temperature for $20 \mathrm{~min}$.

\subsection{Quantification of scopolamine}

The calibration curve from standard solution prepared in ethanol containing scopolamine with concentration ranging from 100 to $1000 \mathrm{mg} / \mathrm{L}$, was used to analyse tropane alkaloid (scopolamine) in Datura innoxia biomass. The data for peak area versus standard concentration was used to construct the calibration curve (Figure 2) which had a linear correlation coefficient, 0.999, for scopolamine. Taking into account the fact that for each standard $10 \mu \mathrm{L}$ were injected, Figure 3 shows the profile of the dependence between the area of the chromatographic peak associated with scopolamine versus the retention time (12.2 $\mathrm{min})$.

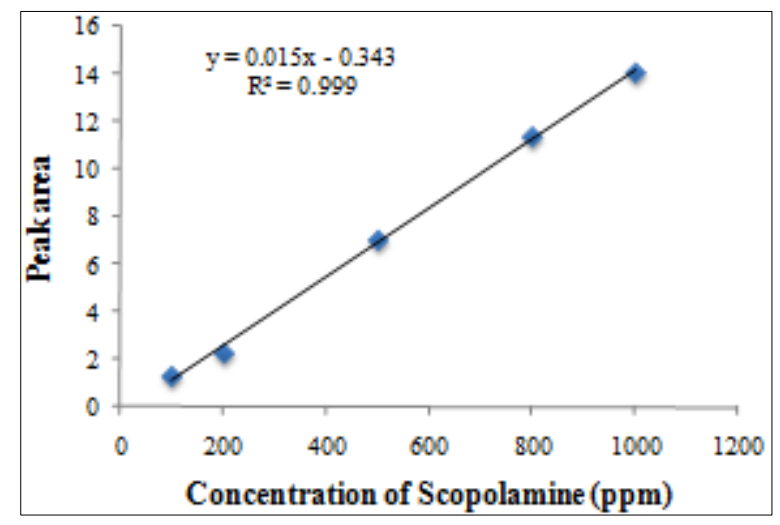

Figure 2. Calibration curve of scopolamine

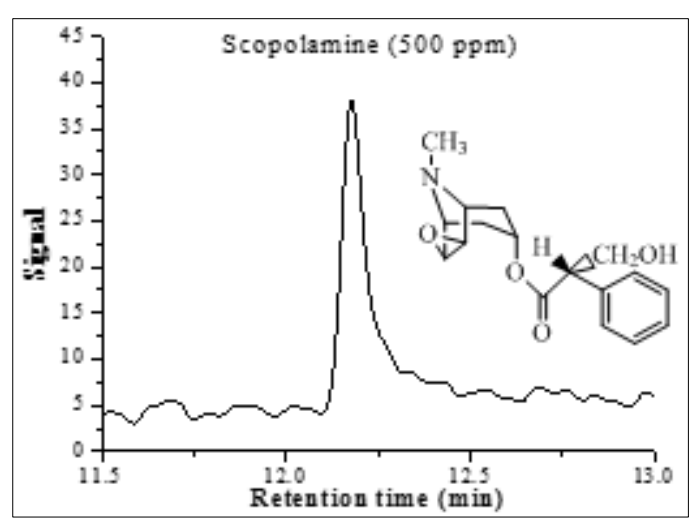

Figure 3. Selected gas-chromatographic Time frame profile of hyoscine (scopolamine) pure standard 


\subsection{Statistical analysis}

Parameters of the standard deviation (SD) were calculated by the fallowing formula [40]:

$$
\sigma=\sqrt{\sum \frac{\left(\mathrm{X}_{\mathrm{i}}-\mathrm{X}\right)^{2}}{\mathrm{~N}}}
$$

where $\sigma$ is the population $\mathrm{SD}, \mathrm{X}$ is the population mean, $\mathrm{X}_{\mathrm{i}}$ is the $\mathrm{i}^{\text {th }}$ element from the population and $\mathrm{N}$ is the number of elements in the population.

\section{Results and discussions}

In the present study the tropane alkaloids, especially scopolamine of Datura innoxia biomass from Romania was successively extracted by two different organic solvents ranging in polarity from 4.0 (1butanol) to 5.2 (ethanol). Scopolamine in the obtained extracts was quantified by GC-FID. Based on this information in Figure 4 and Figure 5 are represented gas chromatographic profiles for Datura innoxia biomas matrix extracts (leaves, flowers, seeds, stem and root) in ethanol and respectively in 1butanol. Taking into account that a good separation was performed each chromatographic profile revealed chromatographic peak for scopolamine. Quantitative investigation of scopolamine has been has been achieved in all matrices from Datura innoxia dry biomass at concentration ranging from $58.90 \pm 0.04$ to $802.58 \pm 0.52 \mathrm{mg} / \mathrm{kg}$ in ethanol extracts and $63.64 \pm 0.03$ to $1294.61 \pm 0.97 \mathrm{mg} / \mathrm{kg}$ in 1 butanol extracts. The results obtained are in accordance with the lipophilicity of scopolamine, so a higher efficiency is achieved using the less polar, 1-butanol [3,33,41].

The highest scopolamine content was found in the root extracted in ethanol $(802.58 \pm 0.52 \mathrm{mg} / \mathrm{kg}$ dry weight) while the highest scopolamine content was in the flowers extracted in 1-butanol (1294.61 $\pm 0.97 \mathrm{mg} / \mathrm{kg}$ dry weight). Dry biomass (mg/kg dry weight) from leaves (58.90 \pm 0.04$)$ flowers $(175.72$ \pm 0.11 ), seeds $(404.41 \pm 1.26)$ and stem $(129.36 \pm 0.14)$ extracted in ethanol have poorer alkaloid content as compared with the same matrices extracted in 1-butanol, such leaves $(461.77 \pm 0.48)$ flowers (1294.51 \pm 0.97$)$, seeds $(675.64 \pm 1.48)$ and stem $(228.61 \pm 0.62)$. Regarding root, scopolamine content $(\mathrm{mg} / \mathrm{kg}$ dry weight) extracted in ethanol $(802.58 \pm 0.52)$ is higher than 1-butanol (63.64 \pm 0.03$)$. The highest content of scopolamine in dried biomass $(1294.61 \pm 0.97 \mathrm{mg} / \mathrm{kg}$ ) was identified in flowers extracted in 1-butanol.

According to the literature [39,42], non-polar solvents are used to solubilize mostly lipophilic compounds (e.g., alkanes, fatty acids, pigments, waxes, sterols, some terpenoids, alkaloids, coumarins but also flavonoids). Medium polarity solvents (aprotic solvents) are used to extract compounds of intermediate polarity (e.g., some alkaloids, flavonoids, phenols), while more polar ones (protic solvents) are used for more polar compounds (e.g., flavonoids glycosides, tannins, some alkaloids, terpenoids, sterols, polyphenols, anthocyanins, saponins). In an extraction referred to as "total", a polar organic solvent (e.g., ethanol, methanol, or an aqueous alcoholic mixture) is employed in an attempt to extract as many compounds as possible. This is based on the ability of alcoholic solvents to increase cell wall permeability, facilitating the efficient extraction of large amounts of polar and medium to low polarity constituents. Since the main driving force in herbal extraction is the concentration gradient, hence the herb-solvent ratio plays an important role; the quantity of extractable matter does get increased with an increase in the volume of extraction solvent $[17,39]$. 

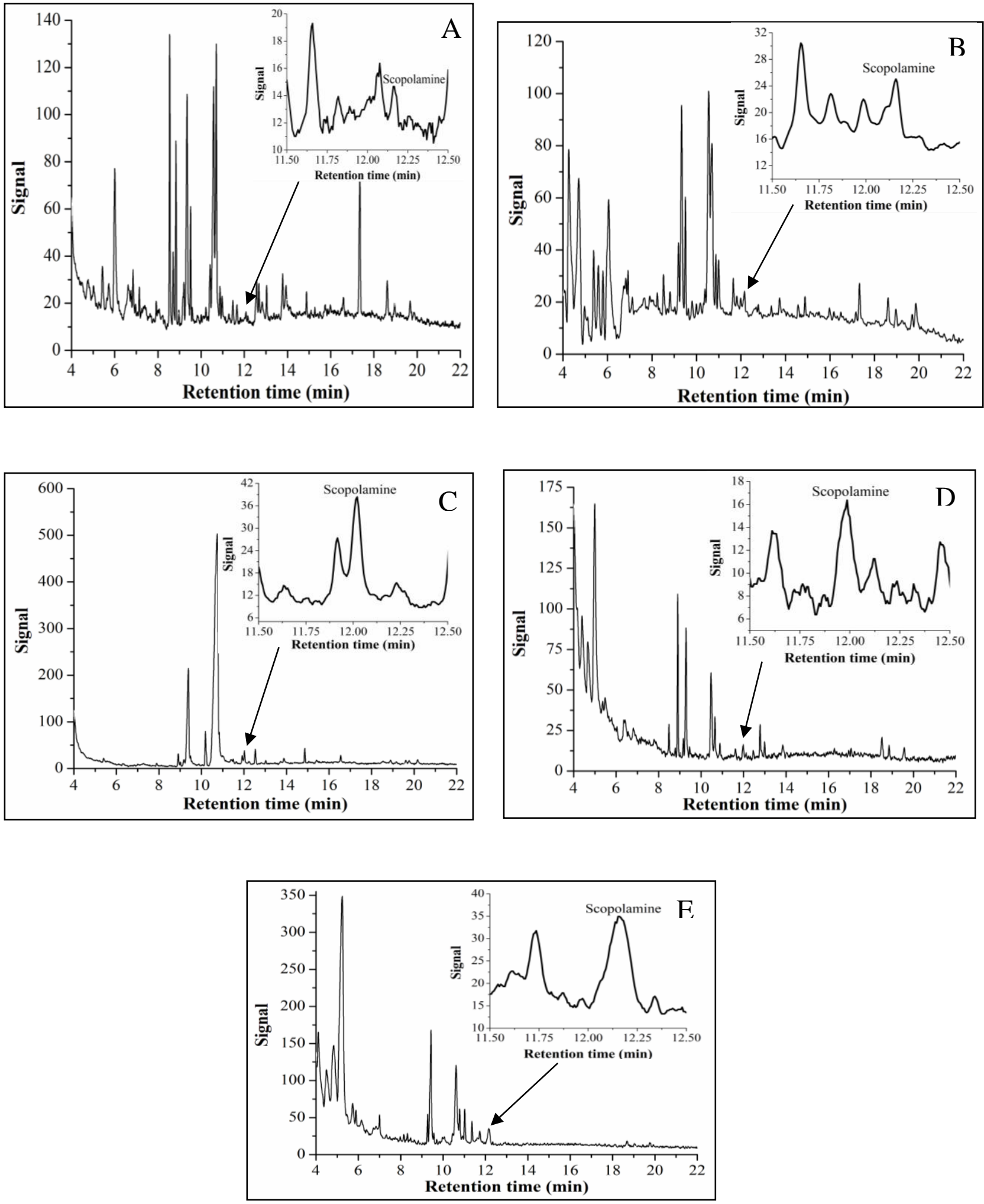

Figure 4. Gas chromatographic profile for Datura innoxia biomass matrix extracts in ethanol: leaves (A), flowers (B), seeds (C), stem (D), root (E), revealing chromatographic peak for scopolamine. 

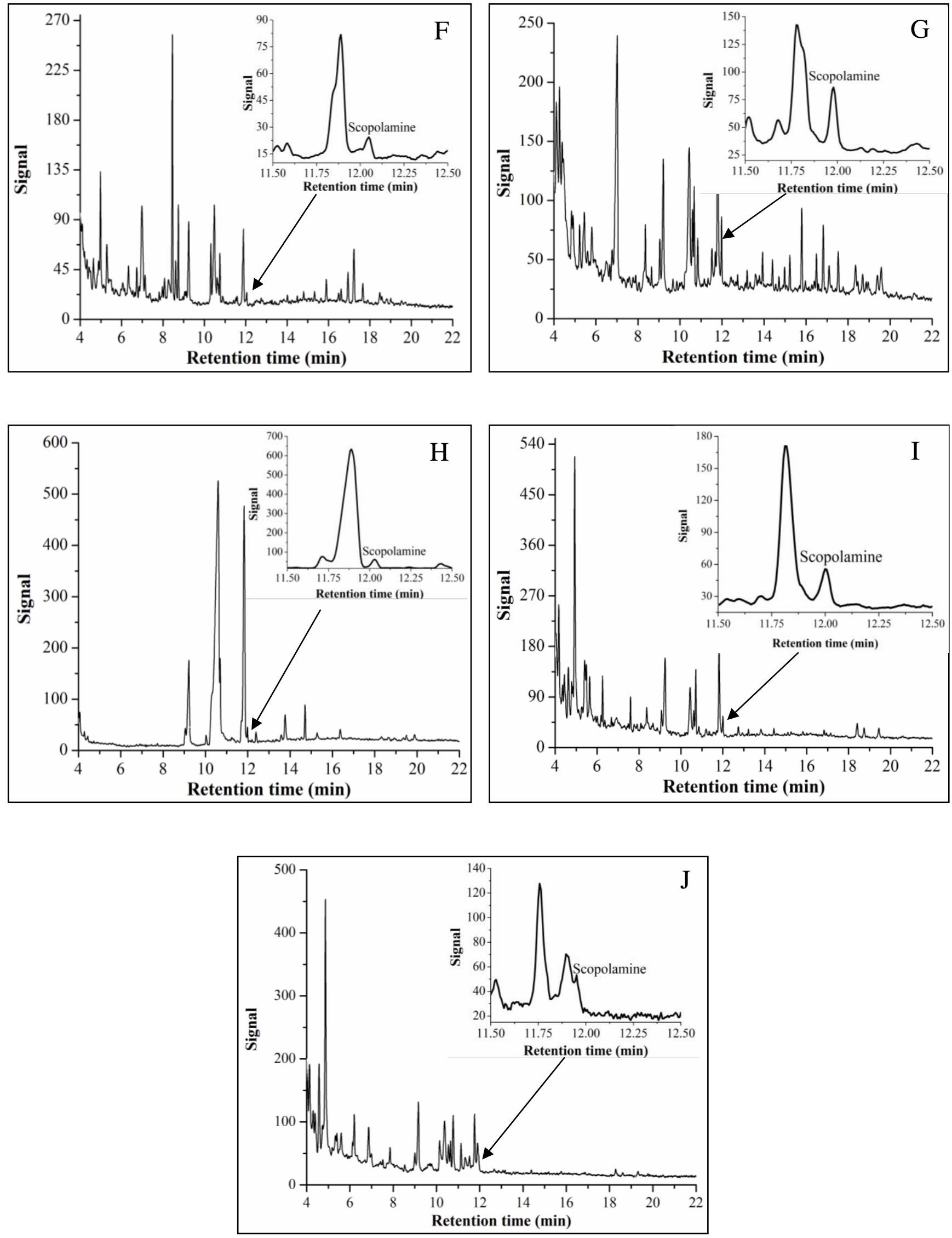

Figure 5. Gas chromatographic profile for Datura innoxia biomass matrix extracts in 1-butanol: leaves $(F)$, flowers $(G)$, seeds $(H)$, stem (I), root $(\mathrm{J})$, revealing chromatographic peak for scopolamine 
Figure 6 indicate a comparative estimation of the concentration for scopolamine in Datura innoxia biomass extracts (ethanol, 1-butanol) using the conventional method, Soxhlet extraction technique. It can be observed that the highest scopolamine content was found in the flowers $(1294.61 \pm 0.97 \mathrm{mg} / \mathrm{kg}$ dry weight) extracted in 1-butanol. The error bars given as $\pm 2 \times$ standard deviation for 3 replicate measurements at the $95 \%$ confidence interval.

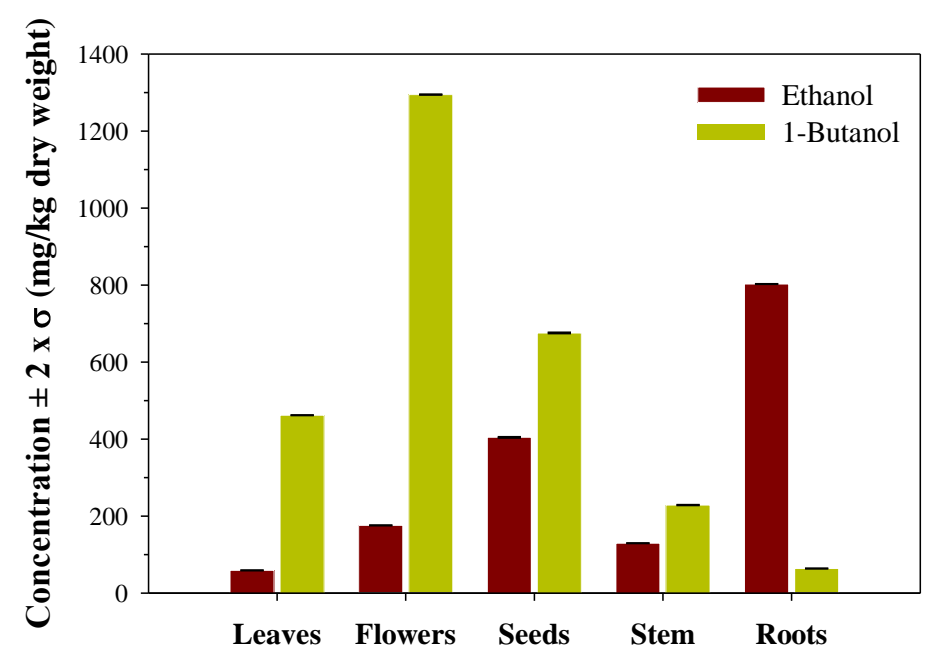

Figure 6. Comparative estimation of the concentration for scopolamine in Datura innoxia biomass using Soxhlet extraction technique

Tropane alkaloids are analyzed in several Datura species using gas-chromatography techniques and scopolamine was one of the most studied compounds. Regarding the values in the literature on concentration of scopolamine in vegetative organs of Datura innoxia, it should be mentioned that these are extremely sporadic.

Levels of scopolamine (1550 mg/kg dry weight) were determined in leaves in Datura stramonium L from America [42] and for Datura stramonium from Poland scopolamine was quantified in roots (1014.1 mg/kg dry weight), stem (193.8 mg/kg dry weight) and leaves (1081.3 mg/kg dry weight) [13]. Regarding tandem techniques, especially GC/MS technique scopolamine was identified in Datura stramonium Italy, range between $14-129 \mathrm{mg} / \mathrm{kg}$ dry weight in all organs of the plant using (LLE) [43] and $678 \mathrm{mg} / \mathrm{kg}$ dry weight in seeds using Soxhlet extraction [44]. On the other hand, for Datura ceratocaula (Netherlands), maceration was used as the extraction method and scopolamine was founded in all vegetative organs, range between $700-3400 \mathrm{mg} / \mathrm{kg}$ dry weight [45]. Based on this quantitative information it is clear that the amount of scopolamine extracted depends on plant species, vegetative organs, place of growing, solvent and extraction procedure.

Quantitative investigation of scopolamine in Datura innoxia from Romania is comparable with other Datura species [13, 42-45] and the results revealed that Datura innoxia from Romania contain similar concentrations compared with other Datura species. It can be observed that the concentration of scopolamine did not only depend on the plant tissues, but also on the geographical origin of samples [15].

\section{Conclusions}

The present results revealed that scopolamine has been identified from ethanolic and 1-butanolic extracts in plant biomass (leaves, flowers, fruits, stem end root) of Datura innoxia using Soxhlet extraction method and quantification by GC-FID analysis. Quantitative analyses of scopolamine are based on the efficiency of Soxhlet extraction. Scopolamine was identified in all vegetative organs from Datura innoxia dry biomass. Quantification of scopolamine using GC-FID was confirmed to be a 
reliable technique providing a good separation of the analyte. Because of the pharmacological properties of scopolamine from different Datura species biomass there is a constant need for acceptable and validated methods for the analysis of this tropane alkaloid in many matrices extracts. In future studies we will continue the investigations in the branch of tropane alkaloid chemistry for other extraction methods.

\section{References}

1.RAMAWAT, K.G., MÉRILlON, J.M., Natural Products. Phytochemistry, Botany and Metabolism of Alkaloids, Phenolics and Terpenes, Springer-Verlag Berlin Heidelberg, 2013, p. 100-1544.

2.HOSTETTMANN, K., WOLFENDER, J.L., TERREAUX, C., Modern screening techniques for plant extracts, Pharm. Biol., 39, 2001, 18-32.

3.MARDARE (BALUSESCU), G., MALUTAN, T., Secondary metabolites from plants: the thin border between beneficent and harmful, Proceedings of the 12th International RAIS Conference on Social Sciences \& Humanities, Princeton, New Jersey, United States of America, 3-4 April 2019, p. 293-299.

4.BERNHOFT, A., Bioactive Compounds in Plants - Benefits and Risks for Man and Animals, Proceedings of the Norwegian Academy of Science and Letters Symposium, Oslo, Norway, 13-14 November 2008, p.11-12.

5.PAWLISZYN, J., Comprehensive Sampling and Sample Preparation Analytical Techniques for Scientists, Elsevier, Oxford, UK, 2012, 597-1826.

6.PÂNZARIU, A.E., MĂLUȚAN, T., MANGALAGIU, I., The hydrolysis of cellulosic materials in ionic liquids, BioResources, 9(1), 2014, 282-292.

7.CIUPERCA, O.T., TEBRENCU, C., IONESCU, E., IACOB, E., VOLF, I., Studies on polyphenols isolated from branches of Prunus spinosa L. species, Rev. Chim., 70(8), 2019, 2897-2902

8.NAIMA, R., OUMAM, M., HANNACHE, H., SESBOU, A., CHARRIER, B., PIZZI, A., CHARRIER - EL BOUHTOURY, F., Comparison of the impact of different extraction methods on polyphenols yields and tannins extracted from moroccan Acacia mollissima barks, Ind Crops Prod, 70, 2015, 245-252.

9.ABDEL-AAL, E.I., HAROON, A.M., MOFEED, J., Successive solvent extraction and GC-MS analysis, for the evaluation of the phytochemical constituents of the filamentous green alga Spirogyra longata, Egypt. J. Aquat. Res., 41(3), 2015, 233-246.

10.LAZAR, L., TALMACIU, A.I., VOLF, I., POPA, V.I., Kinetic Modeling of the Ultrasoundassisted extraction of polyphenols from Picea abies bark, Ultrason. Sonochem., 32, 2016, 191-197.

11.PĂTRĂUŢANU, O.A., CIUPERCĂ, O.T., POPA, V., VOLF, I., Contributions on spruce bark polyphenols ientification using instrumental (UV-VIS Spectrometry), qualitative (Thin Layer Chromatography) and quantitative (HPTLC Densitometry) Methods, Rev.Chim., 71(1), 2020, 39-45.

12.ZENG, Q.H., ZHAO, J.B., WANG, J.J., ZHANG, X.W., JIANG, J.G., Comparative extraction processes, volatile compounds analysis and antioxidant activities of essential oils from Cirsium japonicum Fisch. Ex DC and Cirsium setosum (Willd.) M.Bieb, LWT - Food Sci Technol., 68, 2016, 595-605.

13.SRAMSKA, P., MACIEJKA, A., TOPOLEWSKA, A., STEPNOWSKI, P., HALINSKI, P.L., Isolation of atropine and scopolamine from plant material using liquid-liquid extraction and extrelut ${ }^{\circledR}$ columns, J. Chromatogr.. B, 1043, 2017, 202-208.

14.JI, H., FANNIN, F., KLOTZ, J., BUSH, L., Tall fescue seed extraction and partial purification of Ergo T alkaloids, Front. Chem., 2, 2014, 1-7.

15.JAKABOVÁ, S., VINCZE, L., FARKAS, Á., KILÁR, F., BOROS, B., FELINGER, A., Determination of tropane alkaloids atropine and scopolamine by liquid chromatography-mass spectrometry in plant organs of Datura Species, J. Chromatogr.. A., 1232, 2012, 295-301.

16.BERKOV, S., ZAYED, R., Comparison of tropane alkaloid spectra between Datura innoxia grown in Egypt and Bulgaria, Z. Naturforsch., 59c, 2004, 184-186. 
17.TIWARI, P., KUMAR, B., KAUR, M., KAUR, G., KAUR, H., Phytochemical screening and extraction: A Review, IPS, 1(1), 2011.

18.KUMAR, S., Analytical Techniques for Natural Product Research, CABI, London, UK, 2016, 517.

19.KRENZELOK, E.P., Aspects of Datura poisoning and treatment, Clin. Toxicol., 48, 2010, 104110.

20.EL BAZAOUI, A., BELLIMAM, M.A., SOULAYMANI, A., Tropane alkaloids of Datura innoxia from Morocco, Z. Naturforsch., 67c, 2012, 8-14.

21.EL BAZAOUI, A., BELliMAM, M.A., SOULAYMANI, A., Nine new tropane alkaloids from Datura stramonium L. identified by GC/MS, Fitoterapia, 82, 2011, 193-197.

22.DONCHEVA, T., BERKOV, S., PHILIPOV, S., Comparative study of the alkaloids in tribe Datureae and their chemosystematic significance, Biochem. Syst. Ecol., 34, 2006, 478-488.

23.BERKOV, S., ZAYED, R., DONCHEVA, T., Alkaloid patterns in some varieties of Datura stramonium, Fitoterapia, 77, 2006, 179-182.

24.BERKOV, S., DONCHEVA, T., PHILIPOV, S., ALEXANDROV, K., Ontogenetic variation of the tropane alkaloids in Datura stramonium, Biochem. Syst. Ecol., 33, 2005, 1017-1029.

25.DONCHEVA, T., PHILIPOV, S., \& KOSTOVA, N., Alkaloids from Datura stramonium L, $C$. $R$. Acad. Bulg. Sci., 57, 2004, 5-41.

26.BERKOV, S., PAVLOV, A., A Rapid densitometric method for the analysis of hyoscyamine and scopolamine in solanaceous plants and their transformed root cultures, Phytochem. Anal., 15, 2004, $141-145$.

27.PHILIPOV, S., BERKOV, S., GC-MS Investigation of tropane alkaloids in Datura stramonium, $Z$. Naturforsch., 57c, 2002, 559-561.

28.WITTE, L., MÜLLER, K., ALFERMANN, H.A., Investigation of alkaloid pattern of Datura innoxia plants by capillary gas-liquid-chromatography/mass spectrometry, Planta Med., 52, 1987, 192-197.

29.HANDA, S.S., KHANUJA, S.P.S., LONGO, G., RAKESH, D.D., Extraction Technologies for Medicinal and Aromatic Plants, ICS-UNIDO, Trieste, Italy, 2008, 7.

30.VINATORU, M., MASON, T.J., CALINESCU, I., Ultrasonically assisted extraction (UAE) and microwave assisted extraction (MAE) of functional compounds from plant materials, Trends Analyt Chem, 97, 2017, 159-178.

31.SASIDHARAN, S., CHEN, Y., SARAVANAN, D., SUNDRAM, K.M., LATHA, L.Y., Extraction, isolation and characterization of bioactive compounds from plants' extracts, Afr. J. Tradit. Complement Altern. Med., 8, 2011, 1-10.

32.BELWAL, T., EZZAT, S.M., RASTRELli, L., BHAT, I.D., DAGLIA, M., BALDI, A., DEVKOTA, H.P., ORHAN, I.E., PATRA, J.K., DAS, G., ANANDHARAMAKRISHNAN, C., GOMEZ-GOMEZ, L., NABAVI, S.F., NABAVI, S.M., ATANASOV, A.G., A critical analysis of extraction techniques used for botanicals: trends, priorities, industrial uses and optimization strategies, Trends Analytl. Chem., 100, 2018, 82-102.

33.EICH, E., Solanaceae and Convolvulaceae: Secondary Metabolites Biosynthesis, Chemotaxonomy, Biological and Economic Significance, Springer, Berlin, Germany, 2008, 164.

34.ANTOR, M.A., URIBE, A.A., ERMINY-FALCON, N., WERNER, J.G., CANDIOTTI, K.A., PERGOLIZZI, J.V., BERGESE, S.D., The effect of transdermal scopolamine for the prevention of postoperative nausea and vomiting, Front. Pharmacol., 5, 2014, 1-8.

35.***EUROPEAN DIRECTORATE FOR THE QUALITY OF MEDICINES \& HEALTHCARE (EDQM), Hyoscine CRS Safety Data Sheet, Council of Europe, Strasbourg, France, 2015, p.4.

36.BISWASROY, P., PRADHAN, D., PRADHAN, R., Quantitative analysis of hyoscine in different extracts obtained from the seeds of Datura innoxia by RP- HPLC, J. Ayu. Her. Med., 3(4), 2017, 192195. 
37.PUROHIT, S.D., Introduction to plant cell tissue and organ culture, PHI Learning, Delhi, 2013, 178.

38.ARULVASU, C., SHAKTHI, S.K.S., BABU, G., RADHAKRISHNAN, N., Purification and identification of bioactive protein from leaves of Datura inoxia P.mil, Biomed. Prev. Nutr., 4, 2014, $143-149$.

39.REICHARDT, C., Solvents and Solvent Effects in Organic Chemistry, WILEY-VCH Verlag GmbH \& Co. KGaA, Weinheim, Germany, 2003, 388-402.

40.ALI, Z., Bhaskar, S.B., Basic statistical tools in research and data analysis, Indian J. Anaesth., 60(9), 2016, 662-669.

41.MANDAL, S.C., MANDAL, V., DAS, A.K., Essentials of Botanical Extraction. Principles and Applications, Elsevier, Oxford, United Kingdom, 2015, 80-81.

42.SHONLE, I., BERGELSON, J., Evolutionary ecology of the tropane alkaloids of Datura Stramonium L. (Solanaceae), Evolution, 54(3), 2000, 778-788.

43.MIRALDI, E., MASTI, A., FERRI, S., COMPARINI, I.B., Distribution of hyoscyamine and scopolamine in Datura stramonium, Fitoterapia, 72, 2001, 644-648.

44.CALIGIANI, A., PALLA, G., BONZANINI, F., BIANCHI, A., BRUNI, R., A Validated GC-MS Method for the detection of tropane alkaloids in buckwheat (Fagopyron esculentum L.) fruits, flours and commercial foods, Food Chem., 127, 2011, 204-209.

45.BERKOV. S., Alkaloids of Datura ceratocaula, Z. Naturforsch., 58c, 2003, 455-458.

Manuscript received: 28.05. 2020 